VINCENT SHEN

\title{
OBITUARY OF LAO SZE KWANG
}

Prof. Lao Sze Kwang 勞思光 (1927-2012), one of the most important figures in contemporary Chinese philosophy, passed away on October 21, 2012. Professor Lao was most famous for his History of Chinese Philosophy, which is a must-read for scholars and students in Chinese philosophy and intellectual history, as well as his Chinese poems and his engaging critical reflections on Chinese politics and culture.

Lao Sze Kwang was born in 1927 in Xi'an in a family originated from Hunan province, China. He grew up in a difficult period of time in China under Japanese invasion, in which he entered the Department of Philosophy, Peking University in 1946. However, in order to escape from Chinese Communism, he fled to Taiwan in 1949 to continue his study and graduated from the Department of Philosophy, Taiwan University in 1952. He started to teach philosophy in 1955 at the Chu Hai College, Hong Kong, and, since 1964, at the Department of Religion and Philosophy of the Chung Chi College, Chinese Hong Kong University. He held visiting positions and professorship at Harvard University and Princeton University, USA, and National Tsing Hua University, National Normal University, National Chengchi University, Soochow University, and Huafan University, Taiwan. He became Fellow of the Academia Sinica in 2002. Since 2006 he held a Chair Professor position at the Department of Philosophy, Huafan University, Taiwan.

According to his own statements, Lao Sze Kwang's philosophy is motivated and penetrated by his cultural crisis consciousness, because of the fact that he grew up "in a period of anomaly in which traditional Chinese culture lost its effectiveness while modern culture hadn't established a new order." In response to the cultural crisis, his thoughts developed in three stages. In the first stage, the Early Writings ( 7 volumes) explored the future of Confucianism in reference to Hegelian philosophy. In the second stage, he published a threevolume History of Chinese Philosophy, which was a historical clarification of the crisis in Chinese culture and philosophy. This book was

VINCENT SHEN, Professor and Lee Chair in Chinese Thought and Culture, University of Toronto. Specialties: Chinese philosophy, phenomenology, philosophical problems of technology, culture and religion. E-mail: vincent.shen@utoronto.ca

Journal of Chinese Philosophy 40:1 (March 2013) 215-217

(C) 2013 Journal of Chinese Philosophy 
published in both traditional and simplified Chinese with a Korean translation. The third stage consisted of his philosophy of culture in which he referred to both Western and Chinese philosophies to seek for a solution to the cultural crisis. For this, he published Wenhua zhexue jianglu (Lectures on Philosophy of Culture); Xujing yu xiwang: lun dangdai zhexue yu wenhua (Illusion and Hope: On Contemporary Philosophy and Culture); Weiji shijie yu xinxiwangshiji: zhailun dangdai zhexue yu wenhua (The World of Crisis and the New Century of Hope: On Contemporary Philosophy and Culture II).

Through out these three stages, Professor Lao's philosophical focus was on the question of methodology, the philosophical foundation for achieving human virtuous nature, and a solution of cultural crisis. With an open, philosophical mind, he did not limit himself to any closed system, and, therefore, he was not easily classified into any one school. As suggested by the Festschrift entitled Wanfu qianmeng ren shujuan (Ten Thousand Gates Free to Open and Close) in celebration of his eightieth birthday (2010) published by his students, Professor Lao penetrated in and out freely through different philosophical schools, and his focus was on the "gate" that represented the methodology of studying philosophy in general and Chinese philosophy in particular. In short, his concern was on the fundamental questions and the discursive rules of philosophy and culture.

In his magnum opus, Zhongguo zhexue shi (History of Chinese Philosophy), Lao argued that all philosophers and philosophical schools were concerned with some basic questions that he called the jiyuan (fundamental and original) questions. For him, Chinese philosophy's fundamental and original question was the question of subjectivity, and he delineated four meaningful horizons of the self: bodily self, cognitive self, affective self, and virtuous self.

Lao's philosophy emphasized analyticity and criticality, thus he accepted the linguistic turn and critical theory in contemporary Western philosophy. He made a distinction between "conducive discourse" of moral advices and "cognitive discourse" with truth content. For him, traditional Chinese philosophy was most strong in conducive discourse, which should pay more attention now to cognitive discourse in integrating moral theories, moral education and spirituality. Also he discerned two orientations in culture: the constructive and the liberative. For him, culture was teleological, irreversible and revisable, therefore order construction was needed, such as the role of Confucianism in Chinese philosophy and German Idealism in modern Western philosophy. However, all order constructions had their limits and thus needed liberation, such as the role of Daoism in Chinese philosophy and Marxism in modern Western philosophy. Thus, at the later period of his life, he seemed to be 
sympathetic with Habermas' cultural philosophy, which for him was both liberative and constructive.

Lao Sze Kwang was rewarded the Distinguished Academic Achievement Award from the Phi Tau Phi Scholastic Honour Society (2000), the $46^{\text {th }}$ Annual Academic Award of the Ministry of Education (2002), Cultural Prize of the Executive Yuan (2002), twice the National-Endowed Chair Professorship of the Ministry of Education (2002 and 2005), Republic of China, and Doctor honoris causa in Literature conferred by the Chinese University of Hong Kong (2004).

UNIVERSITY OF TORONTO

Toronto, Ontario

\section{ENDNOTE}

1. Lao Sze Kwang, Wenhua zhexue jianglu (Lectures on Philosophy of Culture) (Hong Kong: Chinese University Press, 2002), xiii. 